\title{
Environmental Influence on Hypertension in San Francisco, California.
}

DOMINICAN

UNIVERSITY

of CALIFORNIA
Corinna Louise Venturina Villar, Dr. Brett R. Bayles, Dr. Andria E. Rusk Dominican University of California

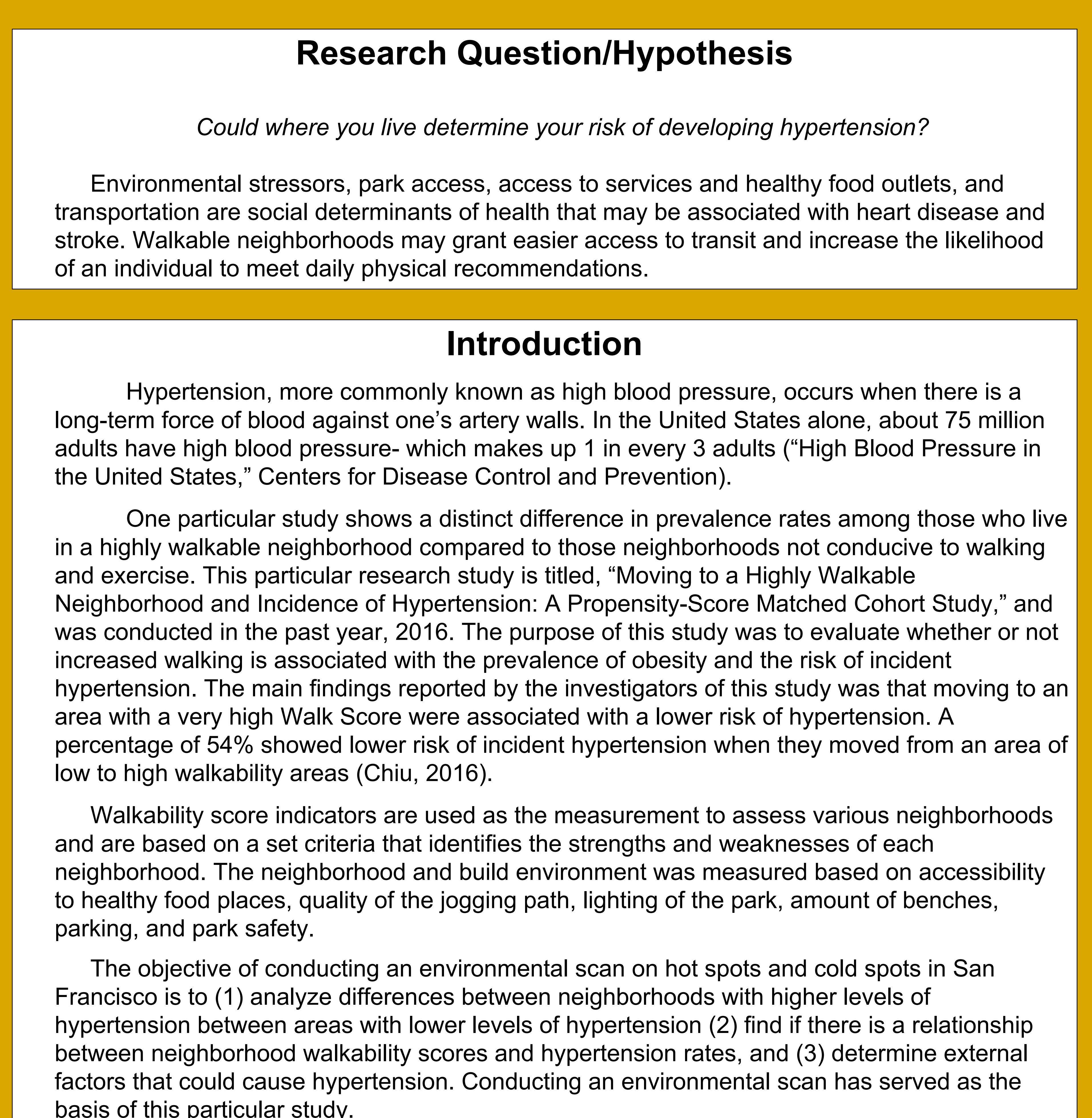

basis of this particular study.

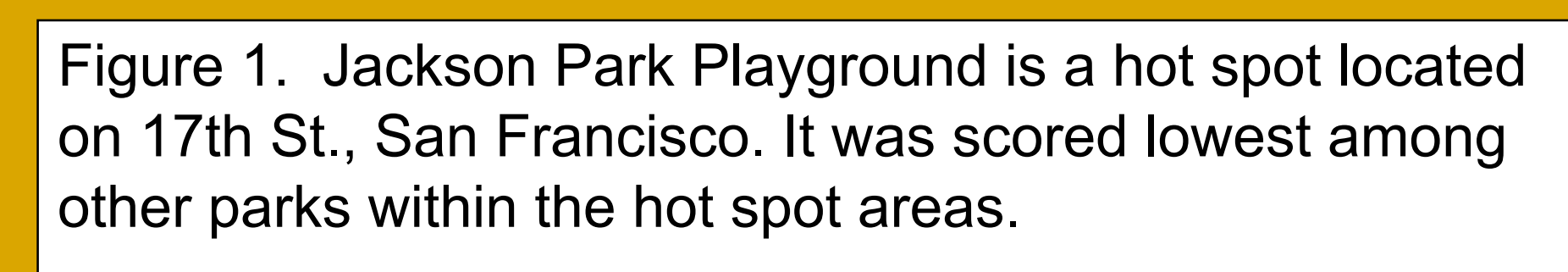

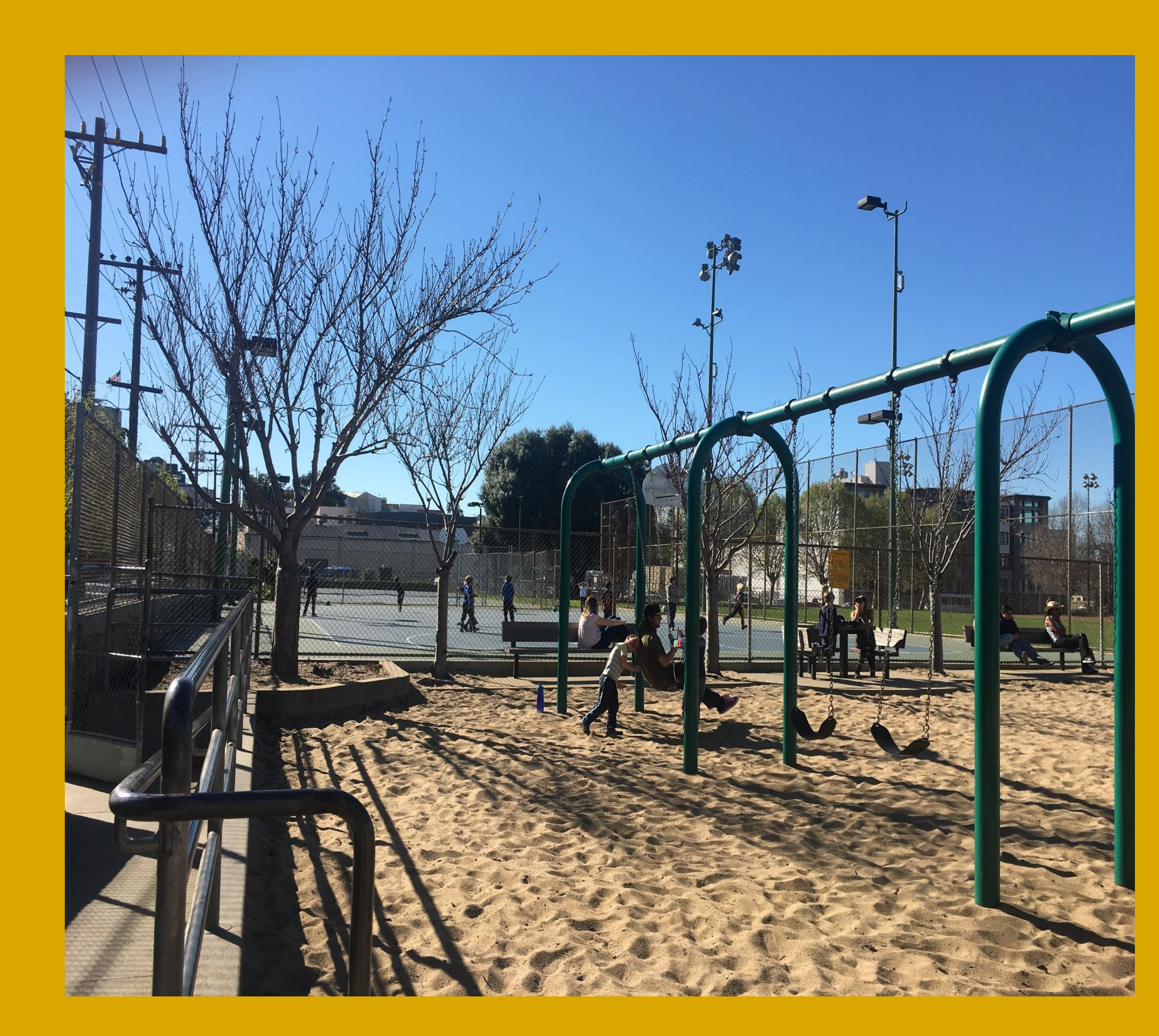

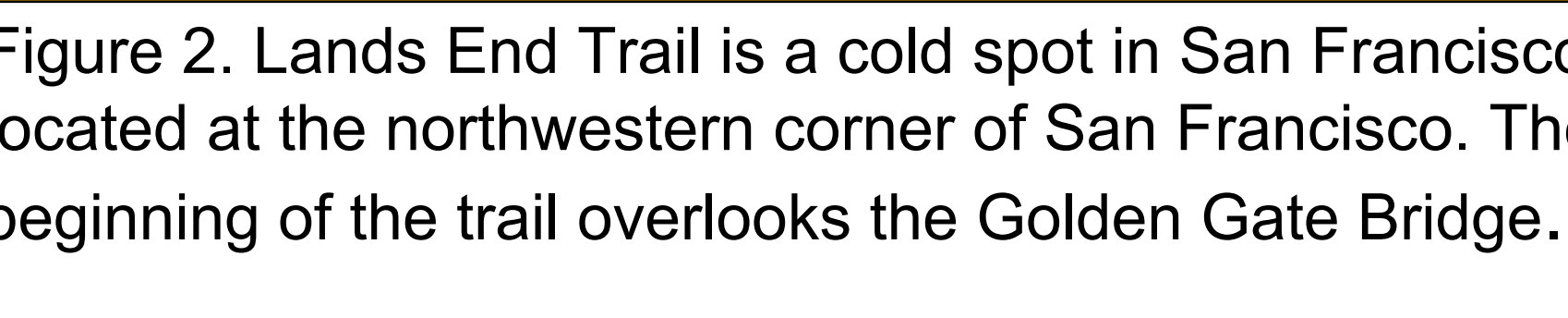

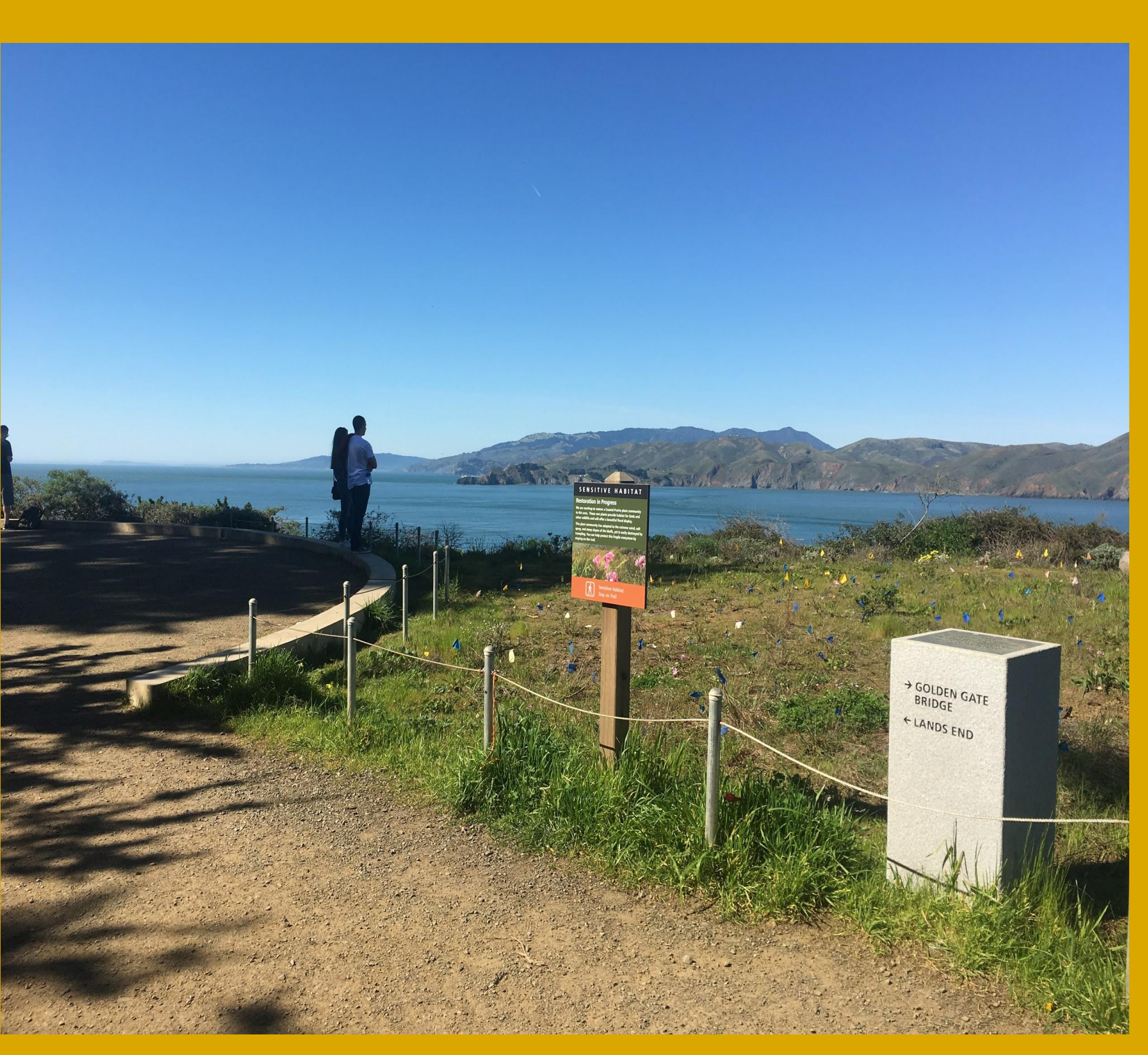

Environmental Score

Method

This study focuses on individuals residing in San Francisco, California. The variables

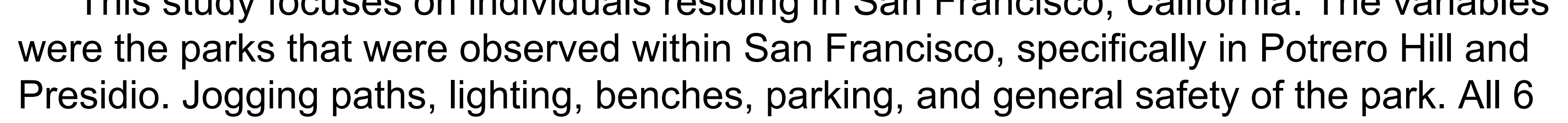
Presidio. Jogging paths, lighting, benches, parking, and general safety of the park. All 6
parks were scored based on how well they meet the expectations of park characteristics parks were scored based on how well they meet the expection

Walkability Score Indicators

Jogging Paths that had a walk path within it scored higher than parks that only had sidewalks
surrounding the park J Joging paths that were cemented and less bumpy received a

surrounding the park. Jogging paths hnat were cemented as
higher score than parks filled with only dirt paths and grass.

Lighting

Parks with light posts illuminating walk paths, benches, and various structures within Ihe park received a higher score than poorly lit parks. Parks that had light posts scattered
along the perimeter of the park and not on the walk paths within the park received a lower score. score.
Benches

Scored based on the number of benches per acre. A more frequent number of provide an adesuab Parking

Parking was scored based on the difficulty to find parking in the surrounding area. Parks with only street parking in downtown San Francisco were scored lower than parks
with a designated parking, since street parking was more limited. Parks located in busy areas with shared parking also received lower scores. Park Safety

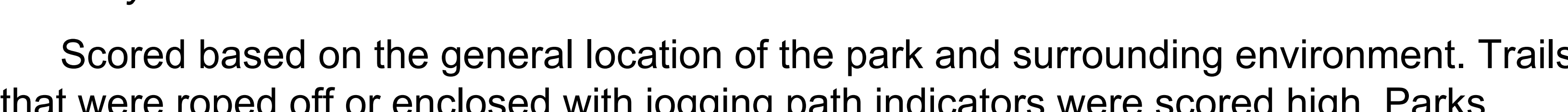
that were roped off or enclosed with jogging path indicators were scored high. Parks
located in a remote area and were poorly illuminated received a low score.
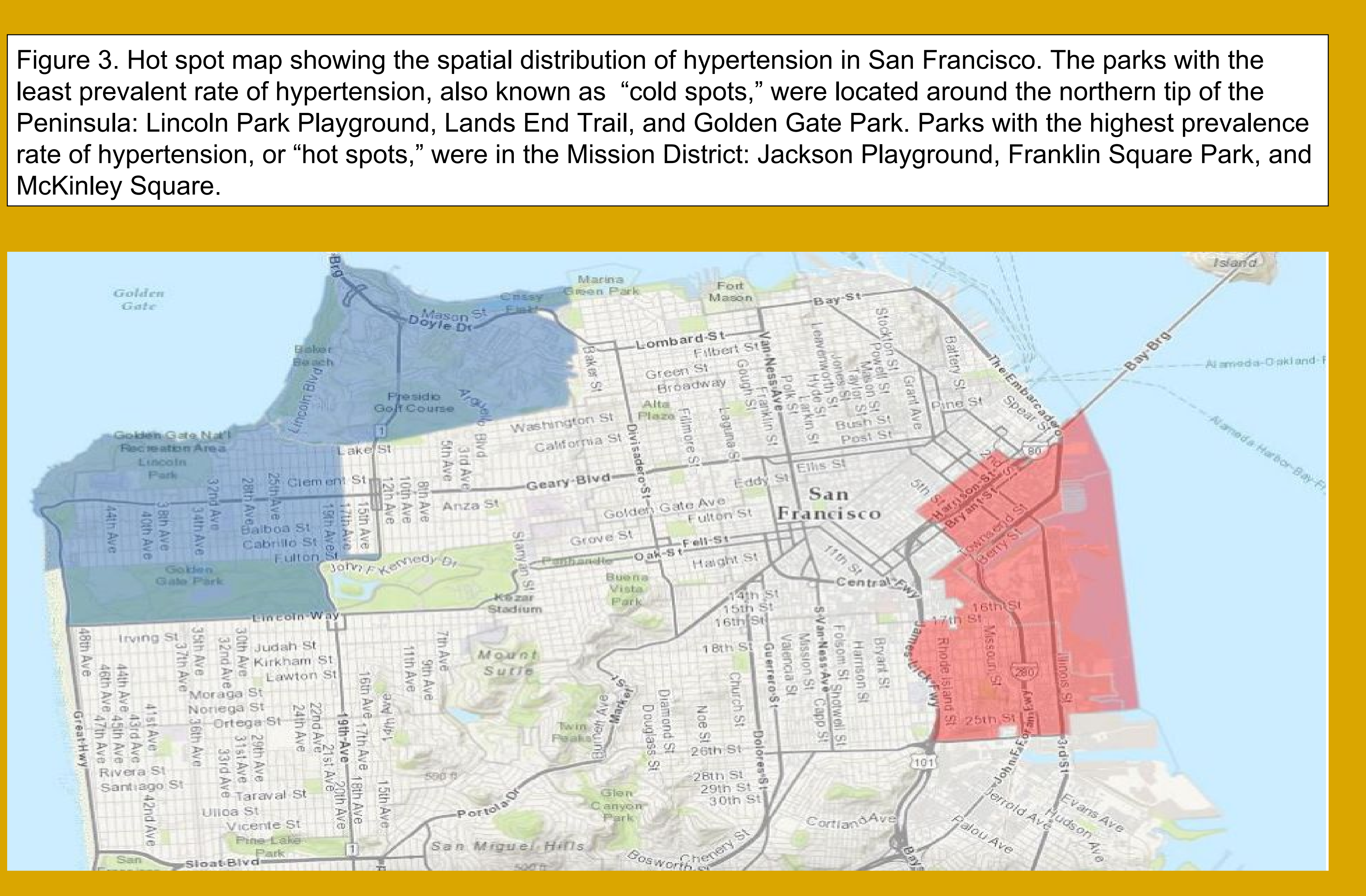

Scored based on the accessibility of a clear path for running within each park. Parks

Results

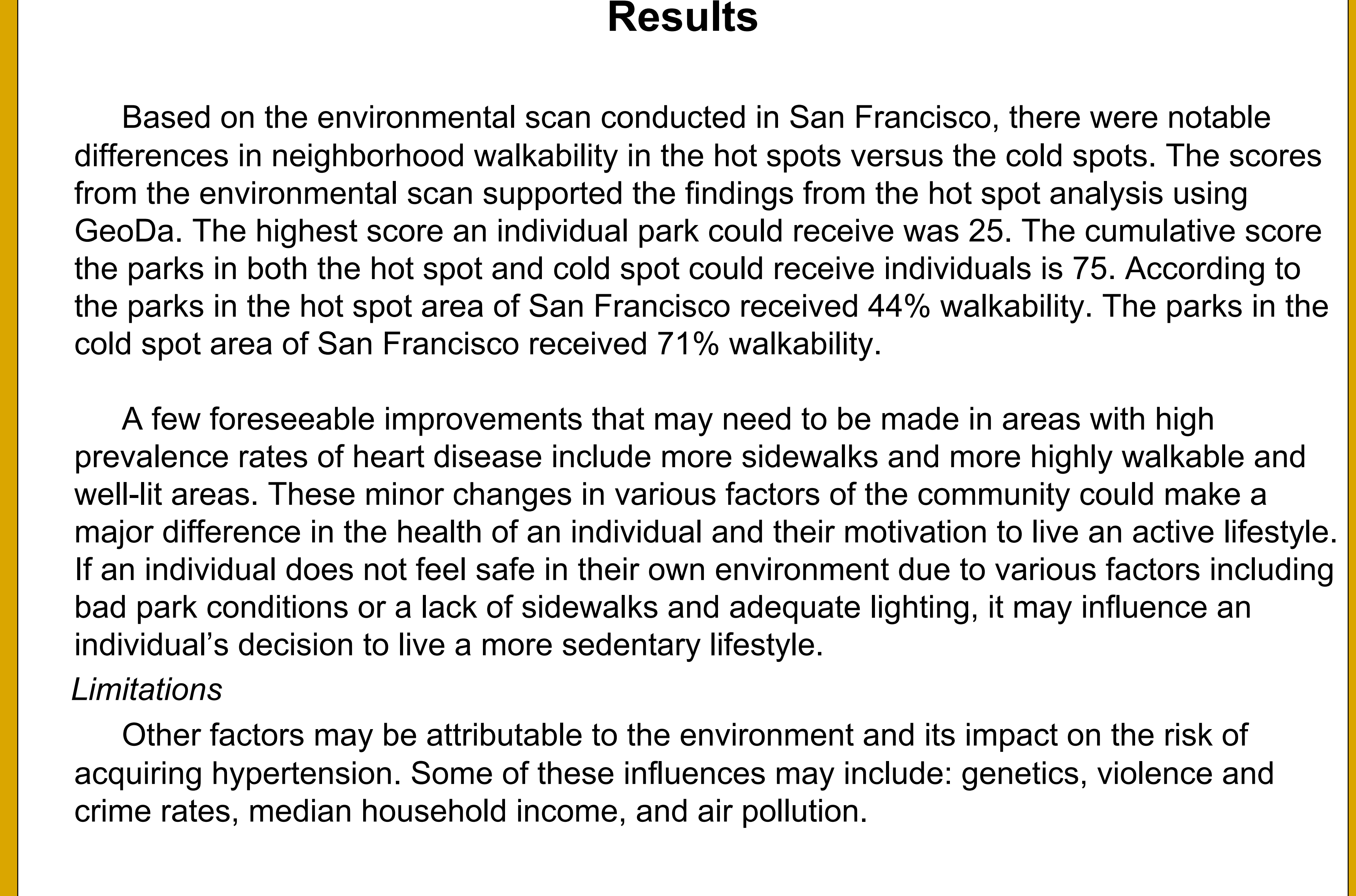

Conclusions

Preventing a rise in high blood pressure to occur in the future will take a great deal of
time and changes that must be made. Utilizing hot spot analysis, as seen in this parlinajor to pinpoint where hypertension has occurred in the past will benefit future research and provide focus on what sets hot spot neighborhoods aside from areas of lower prevalence rates of heart disease. Although limiting variables, such as genetics, may not be accounted for in the process of conducing an environmental scan, measuring aspects of the built and physical environment is significant in determining wh
lives further influences the likelinood of developing hypertension.

\section{References}

